Int. J. Electrochem. Sci., 11 (2016) $7230-7241$

\title{
Inhibition Effect of 1-vinyl-3-ethylimidazolium Bromide for X65 Steel in 0.5 M Sulfuric Acid Solution
}

\author{
Nanxi Chen, Shengtao Zhang ${ }^{*}$, Yujie Qiang, Shenying Xu, Xiaolei Ren \\ School of Chemistry and Chemical Engineering, Chongqing University, Chongqing 400044, P.R. \\ China \\ *E-mail: stzhang_cqu@163.com
}

doi: $10.20964 / 2016.08 .63$

Received: 20 May 2016 / Accepted: 19 June 2016 / Published: 7 July 2016

\begin{abstract}
The corrosion inhibitive effect of 1-vinyl-3-ethylimidazolium bromide ([VEIM]Br) for X65 steel in 0.5 $\mathrm{M} \mathrm{H}_{2} \mathrm{SO}_{4}$ solution has been investigated through electrochemical tests, weight loss, scanning electronic microscopy (SEM) and quantum chemical calculation. The electrochemical and weight loss results revealed that 1-vinyl-3-ethylimidazolium bromide acted as a modest cathodic inhibitor and the inhibition efficiency was up to $85 \%$ when the concentration of inhibitor reached $10 \mathrm{mM}$. SEM observation showed obviously the protection effect using the ionic liquid. The adsorption of [VEIM]Br molecule on the X65 steel surface was found to obey the Langmuir adsorption isotherm. The quantum chemical calculations and molecular dynamics simulation appeared that [VEIM]Br was adsorbed strongly on the X65 steel surface.
\end{abstract}

Keywords: X65 steel, Corrosion inhibition, Ionic liquids, Electrochemical tests, Theoretical study

\section{FULLTEXT}

(C) 2016 The Authors. Published by ESG (www.electrochemsci.org). This article is an open access article distributed under the terms and conditions of the Creative Commons Attribution license (http://creativecommons.org/licenses/by/4.0/). 